\title{
Endoscopic double-layered suturing: a novel tech- nique for closure of large mucosal defects after endoscopic mucosal resection (EMR) or endoscopic submucosal dissection (ESD)
}

Endoscopic mucosal resection (EMR) and endoscopic submucosal dissection (ESD) are widely accepted treatments for early colorectal neoplasms, but complications such as bleeding or perforation are often encountered, especially when the lesions being resected are large in size $[1,2]$. The closure of the mucosal defect reduces the risk of these complications $[3,4]$. Here, we report an effective technique involving the use of a standard endoscope and hemoclips to close a large mucosal defect after endoscopic resection.

The procedure is carried out in two steps. First, to shrink the mucosal defect from the edges we apply an initial set of hemoclips (HX-610-090L, Olympus Medical Systems, Tokyo, Japan) to the submucosal layer of the center of the ulcer floor along the long axis of the ulcer ( $\bullet$ Fig. 1, $\bullet$ Fig. 2, - Fig.3). Second, we apply additional hemoclips to the mucosal layer in the spaces left intentionally between the hemoclips applied in the previous shrinking stage of the procedure ( Fig.4). The mucosal defect is thus closed completely with a total of 10 hemoclips ( Fig.3c and Fig.5). Fig. 6 shows the clinical case at 3 months after ESD: the mucosal defect had healed completely and all hemoclips had dropped off.

Our technique is safe and easy to carry out and no special devices are required. It may be used in not only the colorectum but also potentially the stomach. It cannot be used in the esophagus because of the lack of a serous membrane in this region and in the duodenum as the duodenal muscle is very thin. This technique is based on the method of double-layered suturing of the surgical field following endoscopic closure. We have successfully used the novel method five times in our unit for defects with a mean size of $40 \mathrm{~mm}$. We conclude that this technique is an easy and effective method for complete closure of large mucosal defects after endoscopic resection.

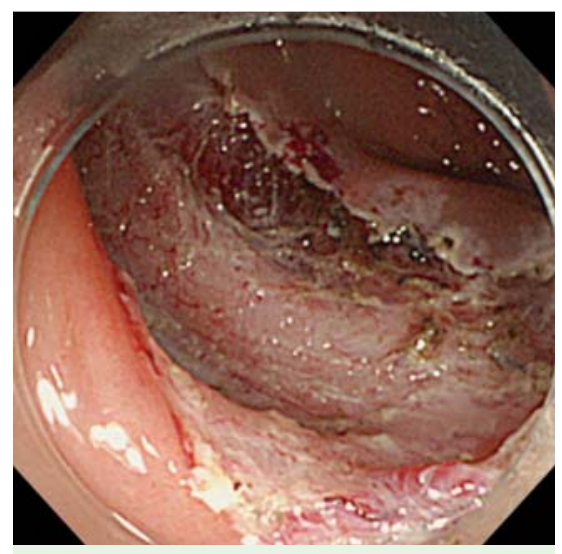

Fig. 1 A large mucosal defect after endoscopic submucosal dissection (ESD) of the ascending colon.

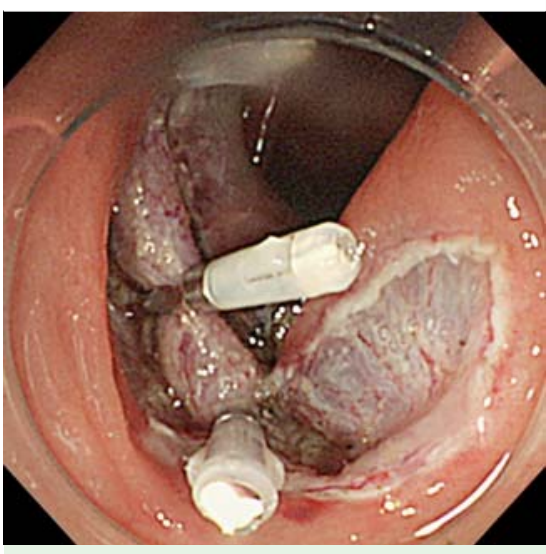

Fig. 2 Initial attachment of two hemoclips to the submucosal layer of the center of the ulcer in the longitudinal direction.

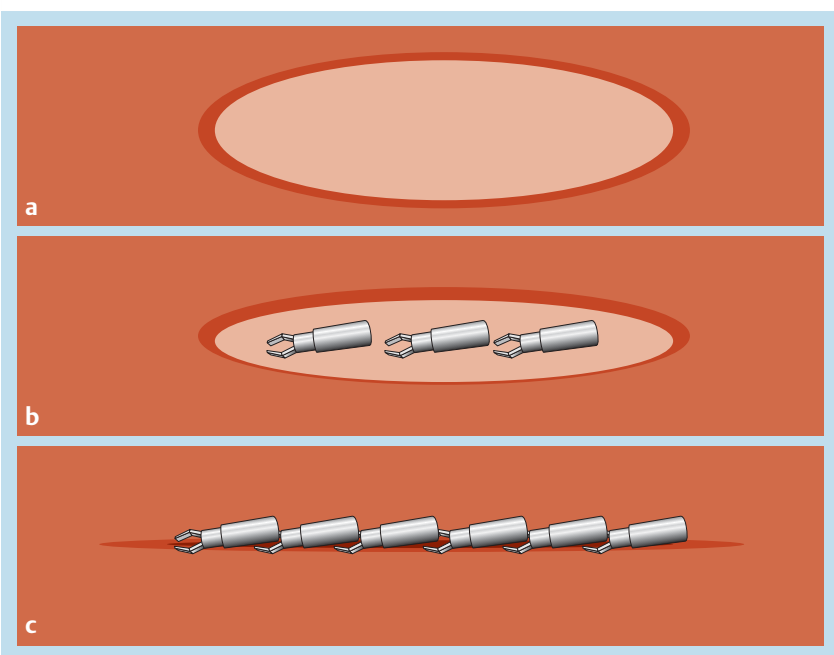

Fig.3 Schematic showing the endoscopic double-layered suturing method. a Mucosal defect after endoscopic mucosal resection (EMR) or endoscopic submucosal dissection (ESD). b An initial set of spaced hemoclips applied onto the submucosal layer of the center of the ulcer floor in a longitudinal direction to shrink the defect. c More hemoclips applied onto the mucosal layer in the spaces left intentionally between the first set of hemoclips in the previous shrinking procedure. 


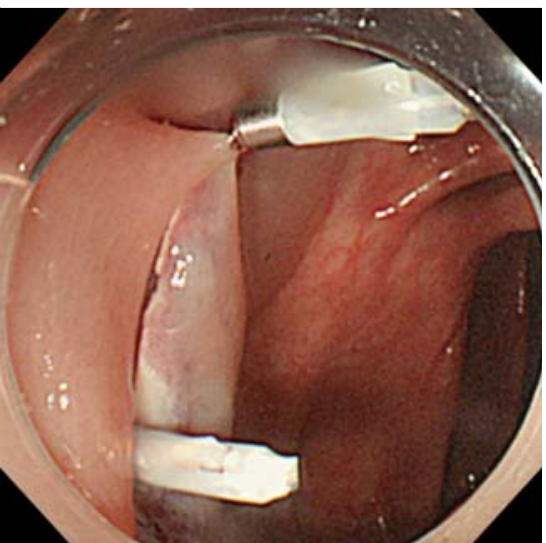

Fig. 4 The second set of hemoclips applied onto the mucosal layer in the spaces between the hemoclips applied in the first stage.

\section{S. Tanaka' , T. Toyonaga ${ }^{1}$, D. Obata ${ }^{1}$, T. Ishida', Y. Morita', T. Azuma' ${ }^{1}$}

${ }^{1}$ Division of Gastroenterology, Department of Internal Medicine, Graduate School of Medicine, Kobe University, Hyogo, Japan

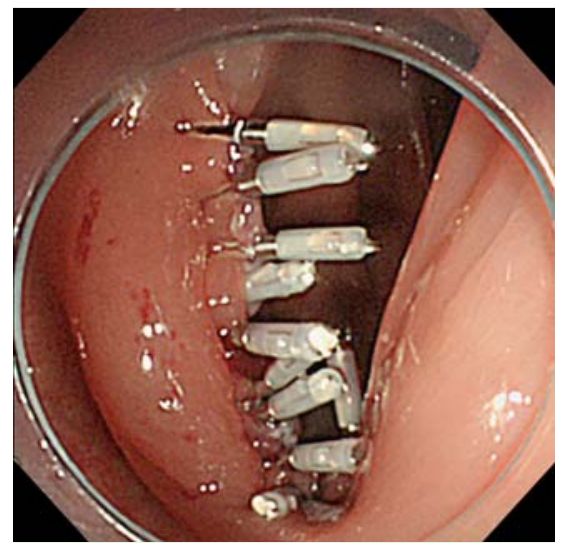

Fig. 5 Complete closure of the defect with a total of 10 hemoclips.

\section{References}

1 Sano $Y$, Machida $H, F u K$ et al. Endoscopic mucosal resection and submucosal dissection method for large colorectal tumors. Dig Endosc 2004; 16: 588 - 591

2 Heldewein $W$, Dollhopf $M$, Rösch $T$ et al. The Munich polypectomy Study (MUPS): prospective analysis of complications and risk factors in 4000 colonic snare polypectomies. Endoscopy 2005; 37: 1116-1122

3 Yoshikane H, Hidano H, Sakakibara A et al. Endoscopic repair by clipping of iatrogenic colonic perforation. Gastrointest Endosc 1997; 46: 464-466

4 Taku K, Sano Y, Fu K-I et al. latrogenic perforation at therapeutic colonoscopy: should the endoscopist attempt closure using endoclips or transfer immediately to surgery. Endoscopy 2006; 38: 428

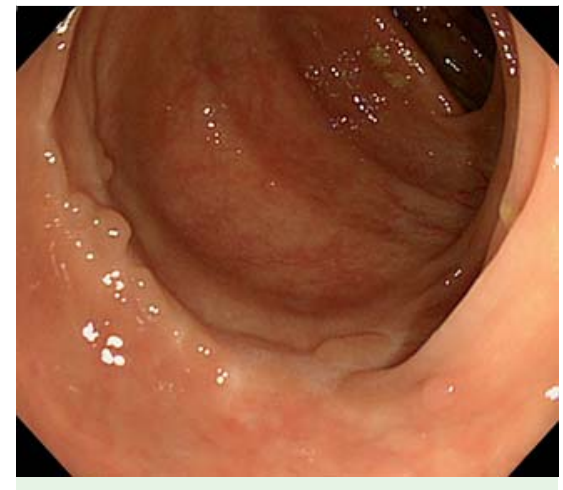

Fig. 6 View 3 months after endoscopic submucosal dissection (ESD).

\section{Bibliography}

Dol http://dx.doi.org/

10.1055/s-0031-1291673

Endoscopy 2012; 44: E153-E154

(c) Georg Thieme Verlag KG

Stuttgart · New York

ISSN 0013-726X

\section{Corresponding author}

\section{T. Toyonaga}

Division of Gastroenterology

Department of Internal Medicine

Graduate School of Medicine

Kobe University

7-5-1 Chu-o-ku

Kusunoki-Cho

Kobe

Hyogo 650-0017

Japan

toyonaga@med.kobe-u.ac.jp 